\title{
Percutaneous Vertebroplasty as a Treatment for Osteoporotic Vertebral Compression Fractures
}

\author{
Alimov Ijod* and Abdusattarov Khurshid \\ ${ }^{1}$ Department of Traumatology, Orthopedics, Military field Surgery and Neurosurgery, Uzbekistan
}

Submission: March 19, 2018; Published: April 11, 2018

*Corresponding author: Alimov Ijod, Department of Traumatology, Orthopedics, Military field Surgery and Neurosurgery, Tashkent Medical Academy 100109, Tashkent, Farabi Street 2, Uzbekistan, Email: a.neurosurgery@bk.ru

\begin{abstract}
Percutaneous vertebroplasty is a minimally invasive procedure for the treatment of osteoporotic and neoplastic vertebral compression fractures; this procedure involves the injection of bone cement directly into the fractured vertebral body. The purpose of this study was to evaluate the efficacy of percutaneous vertebroplasty for patients with painful osteoporotic vertebral compression fractures. This was a retrospective single-center study; the total number 74 percutaneous vertebroplasty was performed in 41 patients with osteoporotic vertebral body compression fractures of the I and II degrees. Of these 41patients, 5 were male (12\%) and 36(88\%) were female; the average age of the patients was 66 years (range, 55-78 years). The overall procedure time was $51.2 \pm 4.2$ (range, 34-55)min. The average cement volume injected into vertebra was $4.5 \pm 0.54$ (range, 3.4-6.0) ml. The mean follow-up was $16.0 \pm 4.2$ (range, 12-24) months. All patients achieved substantial pain relief after surgery; the Visual Analogue Scale (VAS) score decreased significantly from a pre-operative value of $8.4 \pm 1.2$ to a post-operative value of $2.0 \pm 0.2$ and was maintained at $2.2 \pm 0.4$ at the final follow-up $(\mathrm{p}<0.01)$. Our study confirmed that percutaneous vertebroplasty is effective treatment modality for osteoporotic vertebral compression fractures, which offers short and long-term statistically significant benefits in decreasing pain and increasing mobility.
\end{abstract}

Keywords: Osteoporotic vertebral compression fractures; Percutaneous vertebroplasty

\section{Introduction}

Osteoporotic vertebral compression fractures (OVCFs) are the most common single osteoporotic fractures worldwide, constituting an integral part of the osteoporotic syndrome; they occur in $30-50 \%$ of people over the age of 50 [1]. The OVCFs have a negative impact on health related quality of life and are associated with increased mortality. Conservative management, including bed rest, pain relievers, bracing and physical therapy, may fail to relieve pain and frequently lead to prolonged immobilization, depression and a substantial negative impact on life quality. Percutaneous vertebroplasty (PVP) is a minimally invasive procedure for the treatment of OVCFs; it consists of percutaneous injection of biomaterial, such as Polymethyl methacrylate (PMMA), into the fractured vertebral body [2]. The procedure is well tolerated even under local anesthesia. Biomechanical testing has shown that PVP can restore strength and stiffness of the vertebral body to the pre-fracture levels. The advantages of PVP included are following: reduction in pain, disability, and analgesic use; as well as stabilization of the vertebral fracture [3]. The short-term risk factors of PVP are associated with a cement leakage into the spinal canal or into the venous system; the long-term risk factor of PVP is incidence of new vertebral fracture. The PVP as a treatment mode for painful vertebral compression fractures provided long-term therapeutic effects in $70-95 \%$ of the patients [4]. Cost-effective analysis revealed that PVP is most cost-effective treatment procedure in patients with OVCFs in Japan [5]. Thus, the aim of our study was to evaluate the immediate post-interventional and long-term outcomes after PVP in terms of pain relief.

\section{Material and Methods}

Data were collected retrospectively from the records of patients treated between 2015 and 2017 at the department of "Traumatology, orthopedics, neurosurgery with military surgery" of the Tashkent Medical Academy (TMA). The study was executed in compliance with the Helsinki Declaration and local data protection regulations of TMA. The database included data from patients who signed an informed consent form allowing the use of their clinical data for research purposes. Indications for PVP were the presence of single or multiple vertebral compression fractures of vertebral bodies of the I and II degree with a strong pain syndrome, along with osteoporosis, which was preoperatively diagnosed by dual-energy X-ray absorptiometry (DXA). Patients undergoing vertebroplasty for other conditions such as vertebral metastasis, multiple myeloma or traumatic fractures of the spine were excluded. Contraindications of PVP 
were following: osteomyelitis, discitisor active systemic infection; unstable spinal fracture, patients with diffuse idiopathic skeletal hyperostosis and ankylosing spondylitis; severe uncorrectable coagulopathy; impaired cardiopulmonary function; neurologic deficits and spinal cord compression syndrome; bone fragment retropulsion; allergy to bone cement or opacification agents. The following examinations were made in all the patients prior PVP: detailed clinical evaluation, including a the neurological status; blood test with extended coagulogram; imagining modalities such as such X-ray, magnetic resonance tomography (MRT) or multislice computed tomography (MSCT). Osteoporosis was preoperatively diagnosed by dual X-ray absorptiometry in all patients. In order to evaluate the severity of the pain, the visual analog scale (VAS) was used; this system grades pain based on the following: $0=$ absence of pain, $2=$ mild pain, $4=$ moderate pain, $6=$ severe pain, $8=$ extreme pain $10=$ worst pain. The cemented proportion of the vertebral body was determined using volumetric analysis of the postoperative CT scan of the treated levels.

Statistical analysis was performed using SPSS for Windows version 18.0 (SPSS Inc., Chicago, IL, USA). All variables were analysed using descriptive statistical methods. Data are presented as the mean and standard deviation for continuous variables and as percentages for categorical variables. Comparisons of pain outcomes pre- and postoperatively were made using a paired $t$ test. Differences were considered statistically significant when $\mathrm{p}<0.05$.

\section{Procedure}

The preoperative prophylactic antibiotic cefazolin $1 \mathrm{~g}$, was administered intravenously. The procedure was performed under local anesthesia. The transpedicular approach was used to access the collapsed vertebral body in the thoracic and lumbar spine. The vertebral venography has been used for the identification of potential routes of cement venous leakage. The cement is composed of methyl methacrylate and monomer liquid, which were mixed together. Cement injection was done under continuous lateral fluoroscopic control; it was injected using a 13-gauge cannula. The fractured vertebral body was gradually filled with cement until admissible endpoints. Cement injection was interrupted in case of venous leakage into the veins or spinal canal. Patients were in supine position within 1.5 hour after the procedure, the assessment of vital functions and neurological status were examined in every 15 minutes. The control MSCT or CT of the treated level was performed in the first 2-3 days after the procedure.

\section{Results}

A total of 41 patients (36 females and 5 males) met the inclusion criteria and were treated with PVP and then included in the follow-up program that is still going on. The total number 74 percutaneous vertebroplasty was performed in 41 patients with traumatic compression fractures of vertebral bodies of the I and II degree. Of these 41, 5 participants were male (12\%) and 36(88 \%) were female; the average age of the patients was 66 years (range, 55-78 years). The average operative time was $51.2 \pm 4.2$ (range, 34-55) min. The average cement volume was $4.5 \pm 0.54$ (range, 3.4-6.0) ml. The mean follow-up was $16.0 \pm 4.2$ (range, 12-24) months. The evaluation of the results of treatment was carried out according to the following criteria: dynamics and severity of pain syndrome prior and after percutaneous vertebroplasty, motor activity of the patient, and dependence on analgesics. All patients achieved substantial pain relief after surgery. The VAS score decreased significantly from a preoperative value of $8.4 \pm 1.2$ to a post-operative value of $2.0 \pm 0.2$ and was maintained at $2.2 \pm 0.4$ at the final follow-up $(\mathrm{p}<0.01)$. The extravasation of cement into the venous plexuses was noted in 1 patient, which was the reason of occlusion of small branches of the pulmonary arteries, and clinical presentations of this case was asymptomatic. No other complications were encountered. All patients were able to sustain rapid mobilization within 12$24 \mathrm{~h}$ after procedure, and the mean hospitalization length after PVP was 3.5 days (range 3-5). The long- term results revealed that all patients had significantly improved mobility, and by the end of the first postoperative month and mainstay during following 24 month, there were not any subsequent vertebral fractures. In additionally, during the follow up period the majority of patients reported that decreased usage pain relief medicines or not used (Figure $1 \& 2$ ).

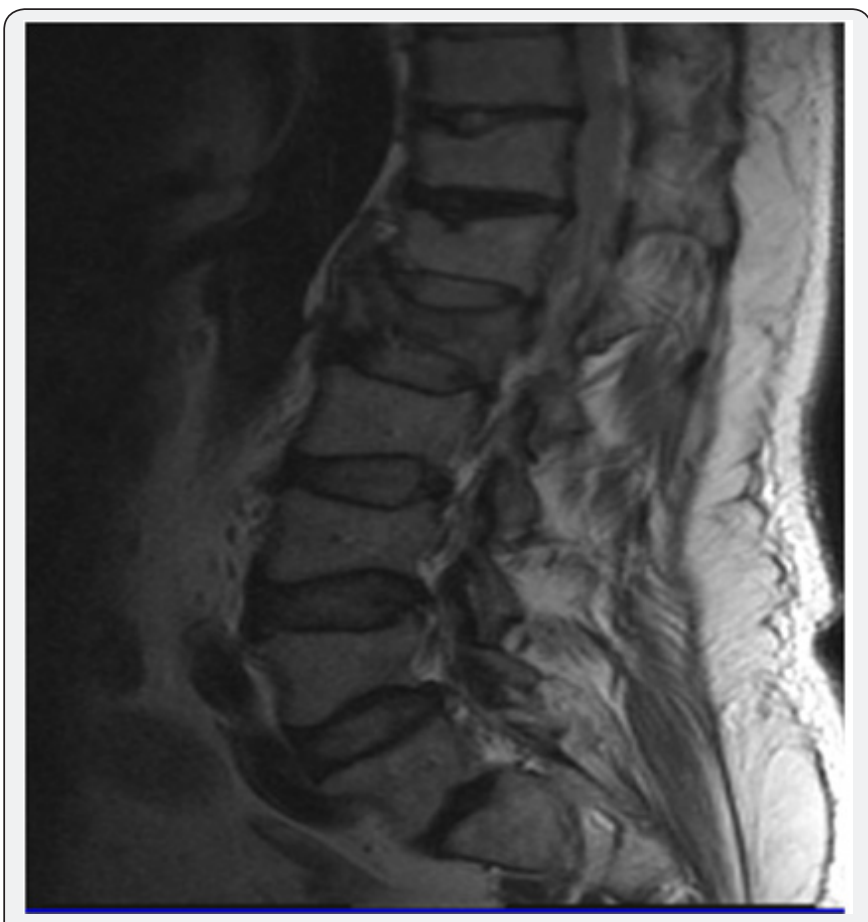

Figure 1: MRI, the T1-weighted sagittal image before surgery. The patient $K$. was 62 years old. There are signs of low-traumatic compression fracture of the body VL2 II degree. 


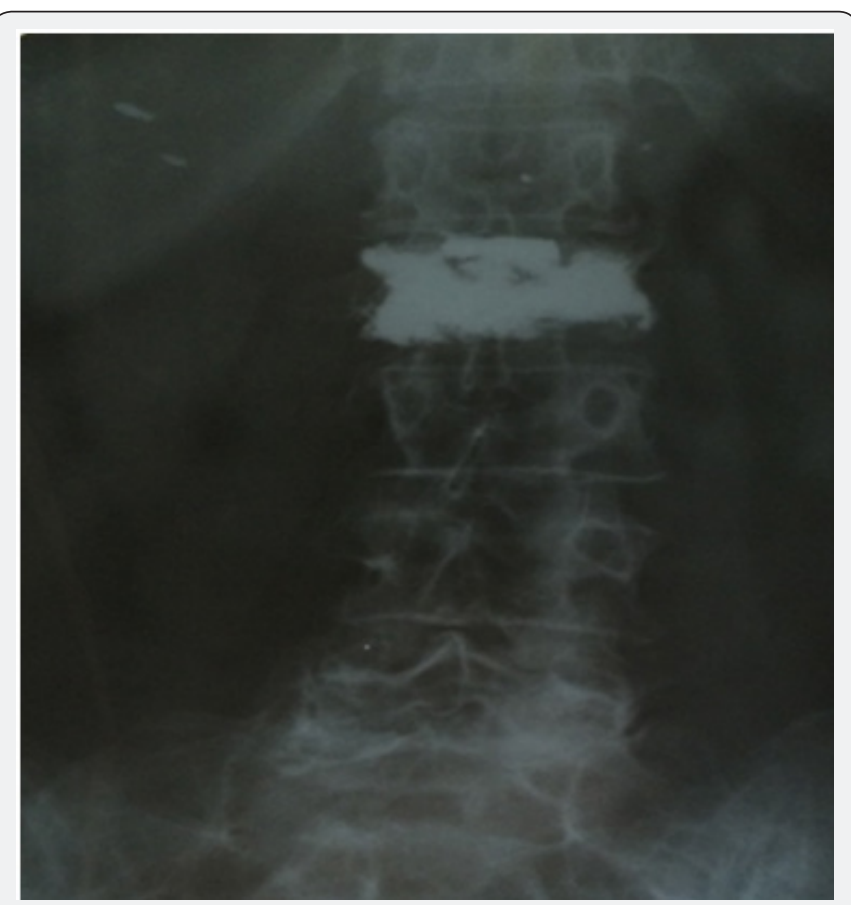

Figure 2: X-ray direct projection imaging. The patient $\mathrm{K}$. was 62 years old after PVP. There are signs of bone cement in the body of VL2.

\section{Discussion}

To date, there are several vertebral augmentation modalities are applied to reduce pain and stabilize compression fractures of the spine; over the decade, the PVP and balloon kyphoplasty (BKP) are used and the novel procedures are radiofrequency kyphoplasty and percutaneous implant techniques [6]. The advantage of PVP/PKP in comparison to conservative management or open surgery has been well established in terms of decreasing pain and improving QOL of patients with OVCFs [7]. Nevertheless, the complications of PVP / PKP are associated with the risk of cement leakage during procedures. The spinal extravasation can lead to cord and nerve injury as well as paravertebral soft tissue and intervertebral disc damage; the venous extravasation into the epidural and vertebral veins can cause cardiac and pulmonary cement embolization. In our series, the incidence of embolism of the pulmonary arteries was $2.34 \%$ (1/41), which was significantly lower then recently reported in literature for PVP/PKP, which was ranged between $3.5 \%$ and $23 \%$ [8]. Therefore, the early postoperative clinical and radiological (CT or MSCT) examinations are recommended to check the proper implants position, but also to detect the possible cement migration.

The controversy exists as to whether PVP/PKP can increase the risk for new OVCFs during follow-up .The experimental biomechanical studies demonstrated that PVP/PKP increased stiffness and strength. Besides, the augmented vertebrae after PVP/PKP increased loading in adjacent vertebrae, inducing subsequent fractures. To resolve the issues, to date the some modifications of injected cements are being developed in experimental studies. Schroder et al. [9], conducted experimental study to examine the influence of adding 10 and $30 \mathrm{vol} \%$ isotonic saline on the biomechanical properties of PMMA vertebroplasty cement. The result of this study demonstrated that compressive stiffness of PMMA-based vertebroplasty cement could be reduced to almost a third by the addition of saline. The probable explanation is an increase in microporosity of cement, which can reduce the risk of subsequent vertebral fractures [9]. Another investigation by Liu et al. [10] tested newly designed CPB cement for replacing the PMMA in PVP and PKP. The biomechanical, biocompatibility, osseointegrative and handling properties of CPB were systematically evaluated in vitro and in vivo. The results of this investigation demonstrated that the biological performance of CPB outperformed the non-degradable PMMA. The authors concluded that CPB has revolutionary potential to replace the PMMA in the applications such as PVP and PKP [10]. Certainly, the above-mentioned two experimental studies are required further evaluation in clinical settings.

\section{Conclusion}

Our study demonstrated that PVP offers statistically significant short and long- term benefits in decreasing pain and increasing mobility for patients with OVCFs. The perioperative complication of cement leakage observed only in one patient, there were not any subsequent vertebral fractures in long- term follow-up.

\section{References}

1. Ballane G, Cauley JA, Luckey MM, El-Hajj Fuleihan G (2017) Worldwide prevalence and incidence of osteoporotic vertebral fractures. Osteoporos Int 28(5): 1531-1542.

2. Denoix E, Viry F, Ostertag A, Parlier-Cuau C, Laredo JD, et al. (2018) What are the predictors of clinical success after percutaneous vertebroplasty for osteoporotic vertebral fractures? Eur Radiol Feb 9.

3. Gonschorek O, Hauck S, Weiß T, Bühren V (2017) Percutaneous vertebral augmentation in fragility fractures-indications and limitations. Eur J Trauma Emerg Surg 43(1): 9-17.

4. Yokoyama K, Kawanishi M, Yamada M, Tanaka H, Ito Y, et al. (2017) Long-term therapeutic effects of vertebroplasty for painful vertebral compression fracture: a retrospective comparative study. $\mathrm{Br} \mathrm{J}$ Neurosurg 31(2): 184-188.

5. Takura T, Yoshimatsu M, Sugimori H, Takizawa K, Furumatsu Y, et al. (2017) Cost-Effectiveness Analysis of Percutaneous Vertebroplasty for Osteoporotic Compression Fractures. Clin Spine Surg 2017 30(3): E205-E210.

6. Genev IK, Tobin MK, Zaidi SP, Khan SR, Amirouche FML, et al. (2017) Spinal Compression Fracture Management: A Review of Current Treatment Strategies and Possible Future Avenues. Global Spine J 7(1): 71-82.

7. Tsoumakidou G, Too CW, Koch G, Caudrelier J, Cazzato RL, et al. (2017) CIRSE Guidelines on Percutaneous Vertebral Augmentation. Cardiovasc Intervent Radiol 40(3): 331-342.

8. Barakat AS, Owais T, Alhashash M, Shousha M, El Saghir H, et al. (2017) Presentation and management of symptomatic central bone cement embolization. Eur Spine J Aug 18. 
9. Schröder C, Nguyen M, Kraxenberger M, Chevalier Y, Melcher C, et al. (2017) Modification of PMMA vertebroplasty cement for reduced stiffness by addition of normal saline: a material properties evaluation. Eur Spine J 26(12): 3209-3215.
10. Liu H, Liu B, Gao C, Meng B, Yang H, et al. (2018) Injectable, biomechanically robust, biodegradable and osseointegrative bone cement for percutaneous kyphoplasty and vertebroplasty. Int Orthop 42(1): 125-132.

\section{Your next submission with Juniper Publishers will reach you the below assets}

- Quality Editorial service

- Swift Peer Review

- Reprints availability

- E-prints Service

- Manuscript Podcast for convenient understanding

- Global attainment for your research

- Manuscript accessibility in different formats

( Pdf, E-pub, Full Text, Audio)

- Unceasing customer service

Track the below URL for one-step submission https://juniperpublishers.com/online-submission.php 